\title{
O jogo roleta probabilística como possibilidade interdisciplinar para o ensino de probabilidade
}

\author{
Josevandro Barros Nascimento (D) Jaqueline Aparecida Foratto Lixandrão Santos (D) \\ Sérgio de Carvalho Bezerra (D)
}

\begin{abstract}
Resumo
Este texto é um recorte de uma pesquisa de mestrado, relacionada a área da Educação Matemática e Ensino de Ciências e Modelagem Matemática. Neste artigo, o objetivo é apresentar o jogo "Roleta Probabilística" e as orientações pedagógicas presentes em cada fase. Considerando as indicações das pesquisas na área da Educação/Educação Matemática/Ensino de Ciências relativas ao ensino de probabilidade que emergem na interação entre os alunos do Ensino Fundamental, professorpesquisador e os jogos pedagógicos digitais, observar se há a motivação dos alunos do $6^{\mathrm{O}}$ ano do Ensino Fundamental no processo de ensino e aprendizagem de probabilidade frente ao jogo pedagógico digital "Roleta Probabilística". Para alcançar tais objetivos, a metodologia presente neste estudo tem perspectiva qualitativa. Além disso, pode ser pensado como um recurso pedagógico inclusivo, pois alunos com diferentes níveis de conhecimento matemático podem desenvolvê-lo.
\end{abstract}

Palavras-chave: Jogos digitais; Probabilidades; Inclusão; Educação Matemática.

\section{Abstract}

This text is an excerpt from a master's research, related to the area of Mathematical Education and Teaching of Sciences and Mathematical Modeling. In this article, the objective is to present the game "Roulette Probabilística" and the pedagogical guidelines present in each phase. With the indications of research in the area of Education / Mathematical Education / Science Teaching regarding the teaching of probability that emerge in the interaction between elementary school students, teacher-researcher and digital pedagogical games and observe if there is the motivation of 6th graders year of elementary school in the process of teaching and learning probability in face of the digital pedagogical game "Roulette Probabilística". To achieve these objectives, the methodology present in this study has a qualitative perspective. In addition, it can be thought of as an inclusive pedagogical resource, as students with different levels of mathematical knowledge can develop it.

Keywords: Digital games; Probabilities; Inclusion; Mathematical Education.

\section{Introdução}

A sugestão do presente trabalho é uma discussão acerca das reais necessidades da matemática nos contextos da diversidade da sala de aula e da inclusão digital. Relaciona-se ao recorte de uma 
pesquisa de mestrado sobre quais contribuições as pesquisas em Educação, Educação Matemática e Ensino de Ciências trazem para a elaboração de jogos digitais.

Uma das propostas que vêm sendo utilizandas como ferramenta no processo de inclusão é o uso dos jogos computacionais [12]. O uso de jogos digitais nas práticas de ensino desenvolve uma aprendizagem lúdica e proporciona uma aula interativa com fases no processo de aprendizagem [13].

A contribuição circunstancial das características do jogo em situação que envolva o ensino evidenciase ante o fato de que o jogo torna-se uma atividade lúdica que contribui para o envolvimento do estudante, uma vez que há o desejo e nteresse do jogador pela própria ação do jogo. Segundo [9], quando passamos a utilizar os jogos nas aulas de matemática envolvemos os alunos em competição saudável e desafios que os motivam a conhecer os seus limites e suas possibilidades de conquistas. Além disso, estudos sobre os conceitos de probabilidades são indispensáveis no contexto em que vivemos e em momentos futuros. Neste sentido o cidadão moderno necessita de habilidades que facilitem uma leitura diversificada para compreender a realidade e desenvolver intervenções. Para a compreensão da probabilidade é importante desenvolver reflexões de situações presentes no cotidiano das pessoas pelo viés dos conceitos matemáticos escolares. Nesse sentido, o ensino da probabilidade pode requerer o desenvolvimento intelectual da crítica e da autonomia, além das concepções dos conceitos matemáticos presentes [11].

Baseando-se nessas ideias, a presente pesquisa buscou contribuições das pesquisas em Educação, Educação Matemática e Ensino de Ciências para a elaboração pedagógica de dois jogos e dos princípios da modelagem computacional que é aplicada à computação gráfica como recurso para sua construção. Neste trabalho, apresentamos o jogo "Roleta Probabilística" que tem como propósito a reflexão e a experimentação de uma situação relacionada à concepção probabilística clássica ou laplaciana.

Na sequência, apresentamos o referencial teórico a partir do qual nos pautamos.

\title{
2. O ensino da matemática e das probabilidades: Algumas Possibilidades
}

Muitos são os questionamentos sobre o ensino e aprendizagem da matemática. São discutidos os porquês de os alunos não apreenderem conceitos de matemáticos, pois não demonstram os conhecimentos "adquiridos" em anos anteriores e saberes fundamentais da matemática [7].

Os Parâmetros Curriculares Nacionais (PCN) indicam que o trabalho pedagógico seja pautado na contextualização sociocultural, onde deve ser estimulada a interação do aluno com a sua realidade:

\begin{abstract}
Num mundo como o atual, de tão rápidas transformações e de tão difíceis contradições, estar formado para a vida significa mais do que reproduzir dados, denominar classificações ou identificar símbolos. Significa: Saber se informar, comunicar-se, argumentar, compreender e agir; Enfrentar problemas de diferentes naturezas; Participar socialmente, de forma prática e solidária; Ser capaz de elaborar críticas ou propostas; e, especialmente, adquirir uma atitude de permanente aprendizado [3]
\end{abstract}

Assim, ao pensarmos nas aulas de matemática precisamos levar em conta possibilidades que estimulem os alunos a aprenderem.

Os Objetos de Aprendizagem, como ferramentas de ensino, podem trazer para a sala de aula muitas possibilidades de aprendizagem que passam por novas abordagens de conteúdos e também pela motivação à aprendizagem em função da mídia em que 
são produzidos. No caso dos jogos educacionais digitais ou softwares educacionais, a interação permitida entre conteúdo e aluno e a possibilidade de aprender usando recursos digitais podem favorecer a apreensão de conteúdo e o interesse pela tarefa. Esse conteúdo, então, é facilmente compreendido e compartilhado entre os alunosusuários de forma interativa, o que exige, desses estudantes, uma atitude responsiva ativa $[2]$

Os PCNs apresentam caminhos para "fazer Matemática", que são: modelagem, etnomatemática, história da matemática, as tecnologias na comunicação e os jogos. Além disso, a resolução de problema é colocada, no referido documento, como ponto de partida para o ensino da matemática. As pesquisas quanto ao uso das Tecnologias da Informação e Comunicação (TIC) indicam que elas podem promover uma abordagem experimental com o seu conhecimento da matemática, favorecendo a investigação em ambiente de ensino e aprendizagem.

Segundo [1], a utilização das tecnologias digitais nas aulas de matemática possibilita que o aluno encare um novo estilo de atividade educacional em que são desafiados a desenvolver a sua autonomia.

Para [5], o uso do computador faz com que a matemática deixe de ser uma associação de conhecimento pronto, que é transmitido aos alunos, e passe a ser um instrumento importante no processo de constituição de conceitos matemáticos. Segundo o referido autor, espera-se que as metodologias com o uso específico dos computadores promovam a competência criativa e o pensamento matemático.

Além disso, o conhecimento probabilístico é de suma importância para o cotidiano das pessoas, pois a sociedade está cercada de informações, as quais têm que interpretar e organizar dados para a compreensão da realidade e tomada de decisões. Dessa forma, pesquisas sobre tais conhecimentos foram desenvolvidas em diversos países. Dentre essas pesquisas, as que que envolvem a linguagem destacam-se, uma vez que possibilitam compreender como os alunos estão entendendo a probabilidade.

De acordo com as pesquisas de [10], os estudos em probabilidade não têm um atributo concreto dos conceitos, mas em muitas das vezes sua percepção tornar ampla que são expressas por meio de notação formal da matemática. Para esse acontecimento é necessário o conhecimento escolar estar ligado ao mundo crítico. [16] afirma que a probabilidade está presente em diferentes contextos associadas em atitudes de mensurar as probabilidades.

Para o ensino de probabilidade, [14] ainda sugere que ele seja desenvolvido, por meio de situações relacionadas à resolução de problemas, em um contexto dinâmico que favoreça a simulação e a experimentação. Dessa forma, os jogos digitais parecem ser um instrumento favorável. Além disso, a autora atenta-nos aos diferentes conceitos probabilísticos.

O conceito clássico ou laplaciano da probabilidade surgiu a partir dos estudos de Laplace. Nesse contexto, a probabilidade é desenvolver o determinismo absoluto e, de acordo com [6], "[...] assumese implicitamente a equiprobabilidade de todos os acontecimentos elementares do espaço amostral". A principal característica do Conceito frequentativo ou empírico da probabilidade está associado ao processo de experimentação. É utilizado o método de repetições que não nos permite obter a probabilidade exata dos acontecimentos, mas apenas uma estimativa de seus resultados [4] O Conceito subjetivista está presente no ideário do sujeito quando ele recorre a seus conhecimentos reais para determinar a probabilidade de um sucesso [15].

O conceito lógico da probabilidade pode estar relacionado ao conceito clássico ou frequencialista. Nesse conceito probabilístico há uma indução - definida por uma semelhança lógica entre o enunciado evidente e as hipóteses que permite uma generalização das conclusões implícitas e contraditórias. Neste conceito, o nível de confirmação é expresso em situações extremas entre certo ou 
impossível [15].

No conceito formal ou axiomático, dado um espaço amostral E e um subconjunto S de E a probabilidade do evento $\mathrm{S}$ é definida pelo quociente entre a medida de $\mathrm{S}$ e a medida de $\mathrm{E}$ [8]. Particularmente, a probabilidade é um número entre 0 e 1, i.e., $0<\mathrm{P}(\mathrm{S})<1$, dessa forma, a probabilidade do espaço amostral impossível é definida por $\mathrm{P}(\mathrm{E})=0$, e uma certa por $\mathrm{P}(\mathrm{E})=1$.

$\mathrm{O}$ conceito geométrico envolve questões análogas à seleção aleatória de pontos em espaços amostrais representados por figuras geométricas.

Segundo [14], os conceitos probabilísticos estão presentes no ideário dos alunos da educação básica, mesmo daqueles "que ainda não tiveram a oportunidade de vivenciar teoricamente conceitos relacionados à probabilidade como medida, ideia de aleatoriedade, probabilidade condicional etc". A autora também ressalta ser importante pensar nas diferentes concepções probabilísticas no trabalho pedagógico com os alunos da educação básica, e para tanto é importante que sejam utilizadas metodologias adequadas.

Pensando em tais considerações, elaboramos dois jogos que se inserem no campo da computação gráfica, uma área de ciência da computação, usando a interface gráfica do Graphical User Interface, que objetiva a geração de imagens e permite o desenvolvimento de interação com dispositivos digitais para o desenvolvimento de jogos.

\section{Metodologia}

Neste trabalho apresentamos um recorte do primeiro momento de nossa pesquisa, que foi o desenvolvimento de jogos digitais para a formação de conceitos probabilísticos de alunos do Ensino Fundamental a partir dos apontamentos de pesquisas desenvolvidas na área da Educação, Educação Matemática e Ensino de Ciências.

Assim, nosso primeiro passo foi organizar questões norteadoras, que foram: quais as contribuições que as pesquisas em Educação, Educação Matemática e Ensino de Ciências trazem para a elaboração de jogos digitais? O que as pesquisas indicam sobre a formação de conceitos sobre probabilidade na Educação Básica? Que elementos precisam ter os jogos digitais para a formação de conceitos sobre probabilidade em aulas do Ensino Fundamental?

$\mathrm{Na}$ sequência realizamos uma revisão bibliográfica visando responder tais questionamentos e, a partir dos apontamentos teóricos, elaboramos dois jogos pedagógicos digitais. Neste artigo, apresentamos o jogo Roleta Probabilística.

\section{Dados e resultados}

O jogo "Roleta probabilística" proporciona aos jogadores reflexões e experimentação dos conceitos probabilístico clássico e frequentista. Além disso, o aluno é levado a aprender os conceitos probabilísticos ao mesmo tempo em que se diverte.

O jogo contém três fases, e cada uma foi organizada da seguinte forma: instruções, desenvolvimento do jogo, resultado das jogadas, questionamento e feedback. Na Figura 1 temos a janela de visualização e de escolha de jogos. O aluno deve optar por um dos dois jogos (Figura 1), Roleta Probabilística ou Meteorito. Junto ao nome dos jogos, apresentamos uma breve explicação sobre o mesmo, para que o aluno tenha ciência do conteúdo matemático envolvido.

Ao optar pelo jogo Roleta Probabilística, o aluno será remetido às telas da Figura 2 e se deparará com uma situação que envolve a análise das chances de números pares e ímpares a serem sorteados 

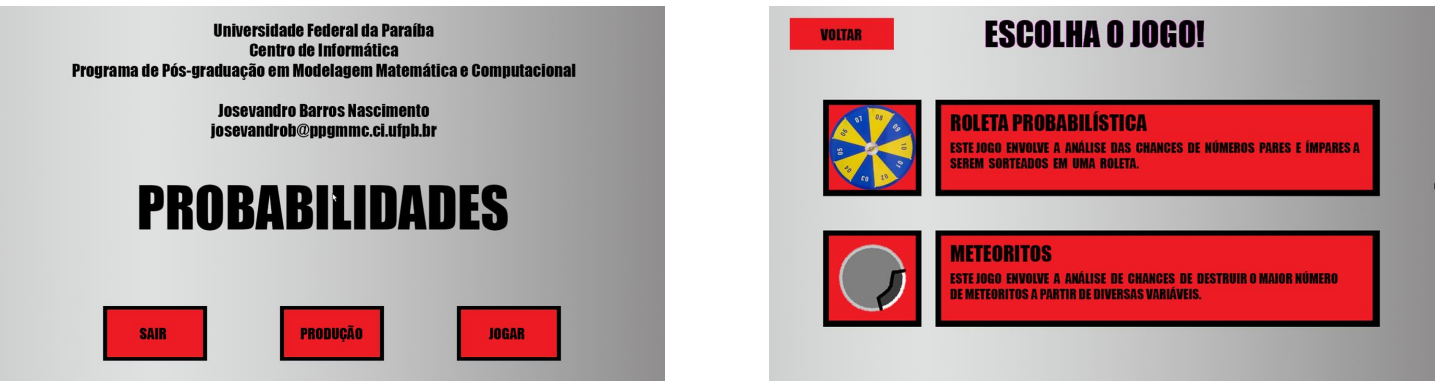

Figura 1: Janela de visualização e escolha do jogo.

em uma roleta.

\section{FASE 1- INSTRUด्̃̃̃ES}

NESTA FASE VOCÊ TERÁ QUE IDENTIFIGAR QUAIS NÚMEROS SÃO PARES E ÍMPARES.

\section{DENTRE OS NÚMEROS ABAIXO INDIQUE GOM "P" PARA OS NÚMEROS PARES E "i" PARA OS NÚMEROS IMPARES}
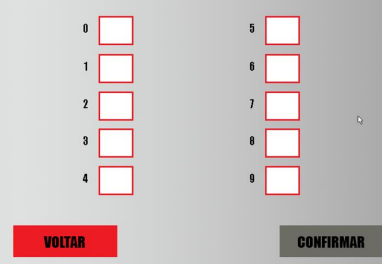

Figura 2: Fase 1: instruções e identificação de números pares e ímpares

Na primeira tela o aluno terá as instruções da fase 1, indicando a ação que irá realizar. Na fase 1 ele terá que identificar os números que são pares ou ímpares, por meio das letras "P" ou "I", tal como apresentado na segunda tela.

Optamos por essa verificação, pois caso o aluno não tenha tal compreensão, ele pode fazer uma avaliação equivocada das chances de sorteios apresentados nas próximas fases. Na sequência os alunos são encaminhados à tela do feedback. 

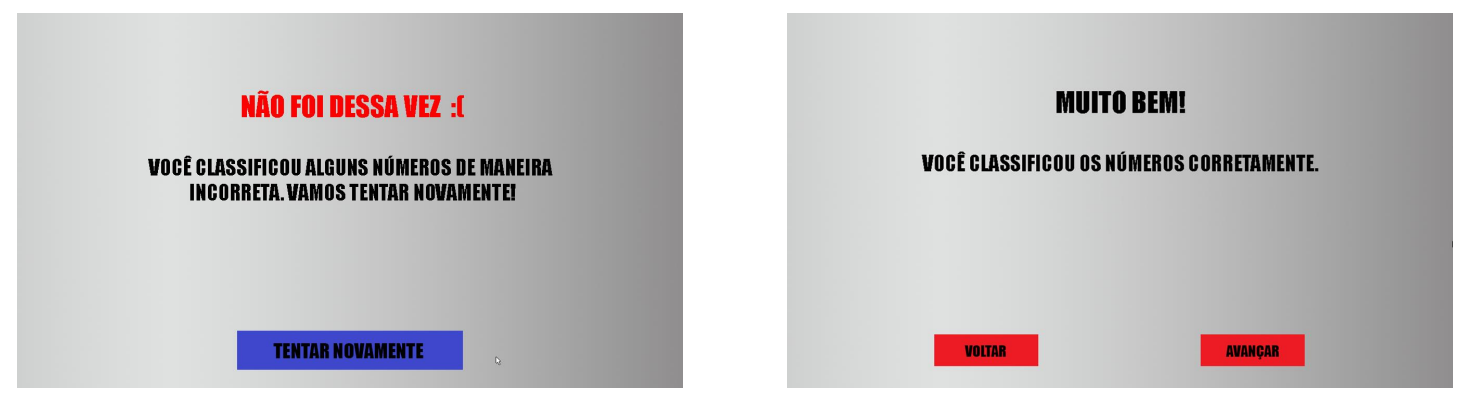

Figura 3: Feedback à resposta do aluno a fase 1

Constatamos em nossos estudos que a comunicação - o feedback dos acertos e erros - deve fazer parte do processo de ensino de matemática e contribui para a formação de conceitos, uma vez que o aluno começa a refletir sobre o porquê do erro e do acerto.

Dessa forma, incluímos em todas as fases do jogo, depois de cada jogada, um feedback ao jogador. Se ele acertou a jogada, depois do feedback, ele pode voltar e jogar novamente ou avançar para a próxima fase. Caso tenha errado, ele deverá jogar novamente. Espera-se, com essa possibilidade, que ele reflita sobre seu erro.
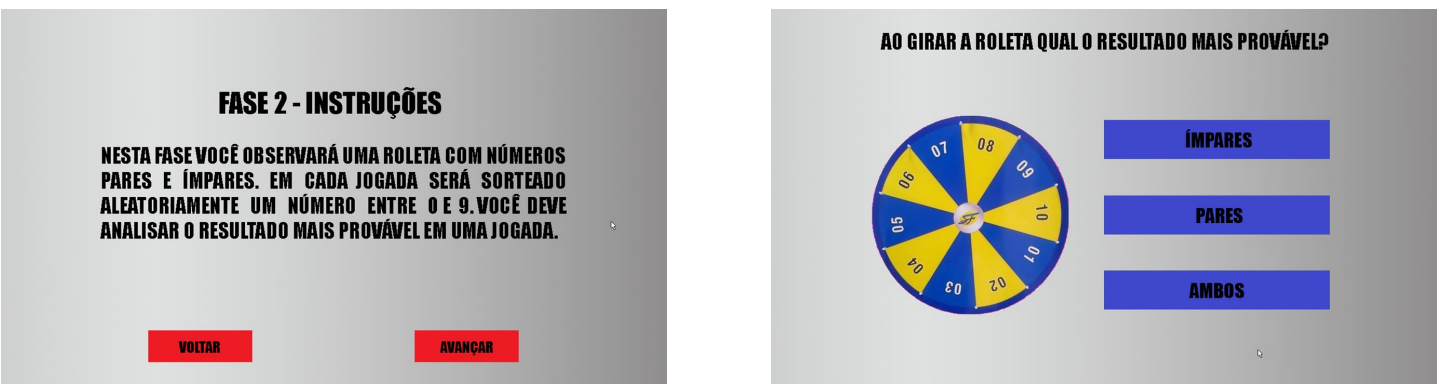

Figura 4: Fase 2: instruções e escolha

Como na fase anterior, no início da fase 2, o jogador tem as instruções (Figura 4). Nessa ele observará os números pares e ímpares que há na roleta e escolherá uma resposta a pergunta "Ao girar a roleta qual o resultado mais provável?". Ele tem como opção de resposta: ímpares, pares ou ambos.

Essa fase contribui para a formação do conceito probabilístico clássico, pois as chances de resultados pares e ímpares no jogo são equiprováveis e ele precisa refletir sobre essa questão para optar por uma resposta. Depois que responder, o jogador será remetido a uma tela com o feedback. 

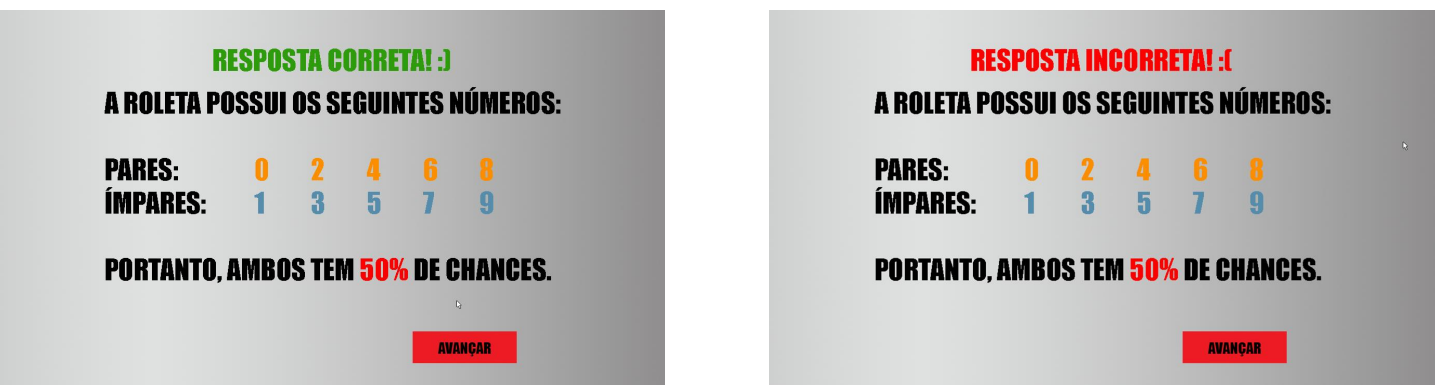

Figura 5: Fase 2: feedback

Na fase 2, o feedback para quem dá a resposta correta ou incorreta é o mesmo. Ele tem a informação dos números da roleta que são pares, dos que são ímpares e o percentual de chances. Nesse caso, ambos têm as mesmas: 50\%. Com essa informação o jogador que acertou tem a confirmação que sua hipótese estava correta; e o que errou, a explicação do porquê de a resposta não ser a que ele escolheu.

Depois que o jogador analisou as chances de os números pares e ímpares serem sorteados, ele vai para a fase 3 para verificar se as chances estimadas na fase anterior acontecem em experimentos .

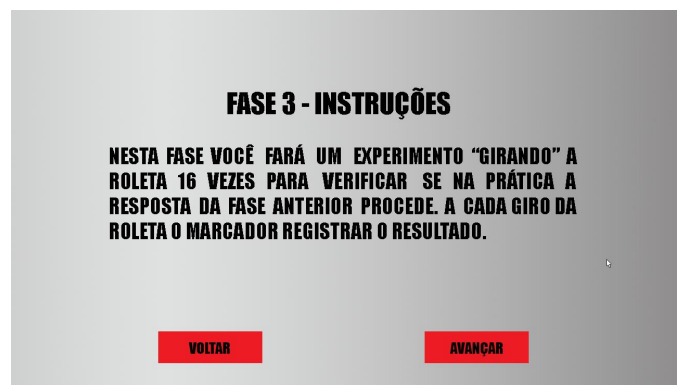

Figura 6: Fase 3: instruções

Quando inicia a fase 3, o jogador depara-se com uma tela que contém a ação que ele deve realizar, que é clicar na roleta para ela girar. Contadores farão a marcação automática dos resultados pares e ímpares obtidos nas jogadas (Figura 7). Essa fase é encerrada após 16 jogadas (giros da roleta). 

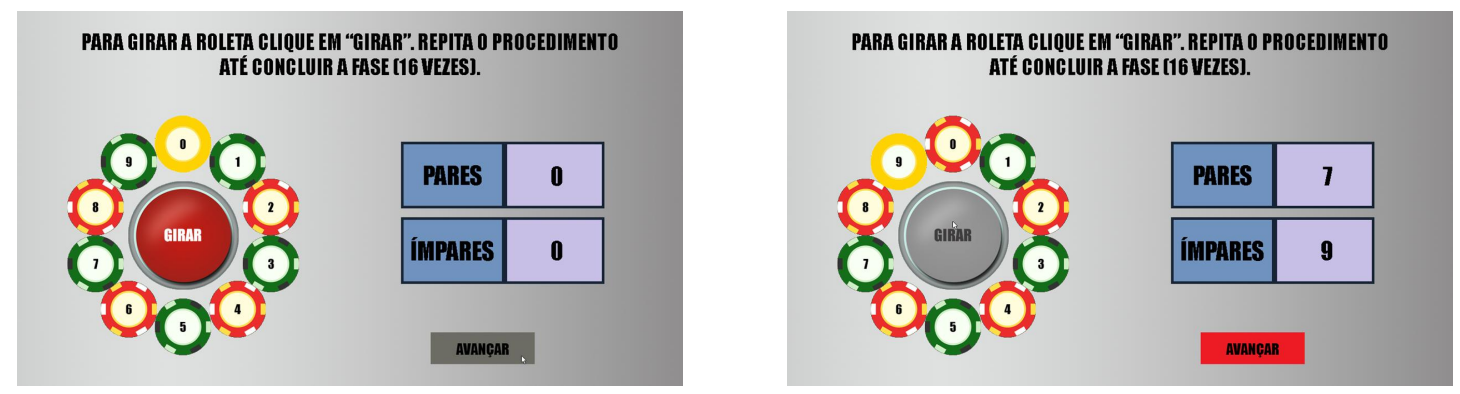

Figura 7: Roleta probabilística: primeiro experimento

Esta fase tem por objetivo envolver o jogador em um contexto em que o conceito probabilístico frequentista faz-se presente. Assim, após "girar" a roleta 16 vezes, o jogo irá parar e o jogador não conseguirá mais girar a roleta e deverá clicar em "avançar". Ao realizar essa ação, será encaminhado à tela com o resultado do experimento.

Optamos por 16 giros, pensando na possibilidade de chegar no resultado estimado e não deixar o jogo monótono com um número excessivo de jogadas. O resultado da roleta é aleatório.

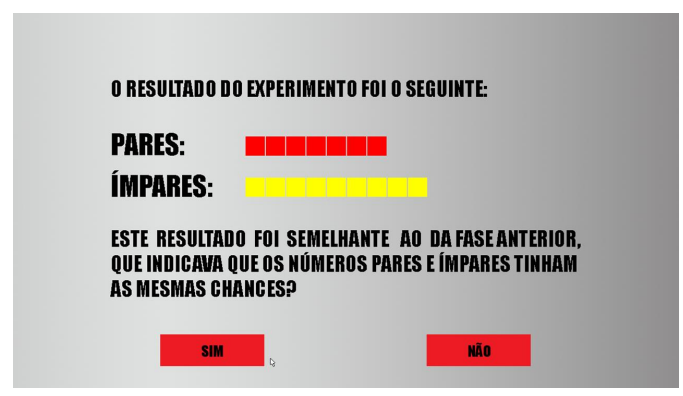

Figura 8: Fase 3: primeiro resultado do experimento

O resultado do experimento é apresentado por meio de um gráfico de barras vertical visando auxiliar na comparação dos resultados obtidos. A pergunta "este resultado foi semelhante ao da fase anterior, que indicava que os números pares e ímpares tinham as mesmas chances?" é apresentada abaixo do resultado, com a opção "sim" ou "não" como resposta. Essa questão tem por objetivo que o aluno reflita sobre as probabilidades estimadas e experimentadas. Com isso, poderá desenvolver noções sobre o conceito de probabilidade frequentista.

Depois de optar pela resposta "sim" ou "não", o jogador será encaminhado à tela do feedback. 

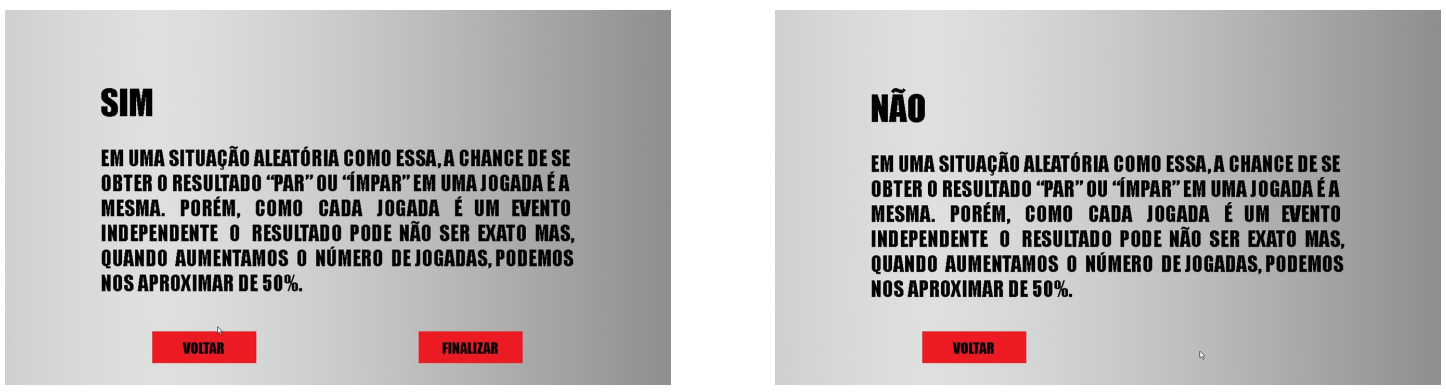

Figura 9: Fase 3:Feedback

Ambas as respostas, sim ou não, trazem as mesmas explicações "Em uma situação aleatória como essa, a chance de se obter o resultado "par" ou "ímpar" em uma jogada é a mesma, porém, como cada jogada é um evento independente, o resultado pode não ser exato; mas, quando aumentamos o número de jogadas, podemos nos aproximar de 50\%". Independentemente da resposta, o jogador pode continuar o experimento que já havia realizado (Figura 9), clicando na palavra "voltar". A diferença nas telas é que se o aluno responder não, ele não terá a opção para finalizar o jogo.

O objetivo de continuar o experimento é que o jogador tenha a possibilidade de constatar que, quando ampliamos o número de jogadas, podemos nos aproximar das probabilidades estimadas.

\section{Considerações finais}

Nossa pesquisa teve como objetivo geral desenvolver jogos pedagógicos digitais para o ensino de probabilidade. Para tanto, pautamo-nos em orientações de pesquisas na área, que nos indicaram que o jogo digital pode ser um recurso pedagógico importante o ensino da Matemática. Além disso, as orientações sobre o ensino de probabilidade apontaram-nos que há diferentes concepções sobre probabilidade - clássica, frequentista, subjetivista, axiomática, lógica e geométrica - e que é importante que situações de ensino possibilitem reflexões sobre as mesmas.

No jogo Roleta Probabilística, o jogador que tiver como estratégia principal a análise das chances das situações poderá ter melhor desempenho no jogo. A elaboração de jogos digitais não é simples: além de questões pedagógicas sobre o ensino da matemática, é preciso conhecimento específica na área de computação gráfica. E não apenas: é importante o diálogo entre as diferentes áreas. Tal fator foi preponderante para o desenvolvimento dos referidos jogos. De mais a mais, preocupamonos em desenvolver os jogos em sala de aula com alunos da Educação Básica, que manifestaram adrenalina e sentimento de prazer em realizar as fases.

Entendemos que o jogo pelo jogo pode não trazer os resultados pedagógicos esperados; é muito importante a mediação do professor e intervenções didáticas, como a discussão coletiva dos resultados e hipóteses. Além de outras propostas de experimentos, como lançamentos de moedas, lançamento de dados etc. Quanto ao jogo, concordamos com [9] em que, para que o jogador jogue com competência, é preciso jogar várias vezes, para que possa analisar as suas jogadas e do adversário, bem como elaborar e testar diferentes estratégias. Consideramos que essa questão possa ser realizada em pesquisas futuras.

Consideramos que a estrutura como os jogos foram organizados - instruções, desenvolvimento do jogo, resultado das jogadas, questionamento e feedback, assim como as diferentes variáveis e con- 
ceitos probabilísticos podem contribuir com a formação do pensamento probabilístico dos alunos no ensino fundamental.

Concordamos com [14, 15], que considera que o desenvolvimento do pensamento probabilístico é fruto de reflexões e intervenções didáticas desenvolvidas em todo o período escolar. Assim, consideramos que "roleta probabilística" pode contribuir com esse desenvolvimento. Além disso, entendemos que os jogos digitais são ferramentas para uma inclusão na diversidade, e as relações só nos faz refletir a importância da investigação em jogos pedagógicos digitais.

\section{Referências}

[1] ALMIRO, João. Materiais manipuláveis e tecnologia na aula de Matemática. O professor e o desenvolvimento curricular, 2004.

[2] ARAUJO, NukáciaMeyre Silva; RIBEIRO, Fernanda Rodrigues and SANTOS, Suellen Fernandes dos. Jogos pedagógicos e responsividade: ludicidade, compreensão leitora e aprendizagem. Bakhtiniana, Rev. Estud. Discurso [online]. 2012, vol.7, n.1. ISSN 2176-4573.

[3] BRASIL. Secretaria de Educação Média e Tecnológica. Parâmetros Curriculares Nacionais: Ensino Médio. Ministério da Educação, Secretaria de Educação Média e Tecnológica. Brasília: MEC/Semtec, 2002.

[4] CIRINO M. M. A intermediação da noção de probabilidade na construção de conceitos relacionados à cinética química no Ensino Médio. 2007. 201f. Dissertação (Mestrado em Educação para a Ciência). Faculdade de Ciências, UNESP, Bauru, 2007.

[5] D'AMBROSIO, Beatriz S. Como ensinar matemática hoje. Temas e Debates. SBEM. Ano II, v. 2,1989 .

[6] FERNANDES, José Antônio. Intuições e aprendizagem de probabilidades: uma proposta de ensino de probabilidades no 9.o ano de escolaridade. 1999. 461 f. Tese (Doutorado em Educação) -Universidade do Minho, Braga, 1999

[7] FIORENTINI, Dario et al. Uma reflexão sobre o uso de materiais concretos e jogos no Ensino da Matemática. Boletim da SBEM-SP, v. 4, n. 7, 1990.

[8] GODINO, Juan; BATANERO, Maria Carmen; CAÑIZARES, Maria José. Azar y probabilidad. Madrid: Síntesis, 1996.

[9] GRANDO, Regina Célia et al. O conhecimento matemático e o uso de jogos na sala de aula. 2000.

[10] GAL, Iddo. Towards probability literacy for all citizens: building blocks and instructional dilemmas. In: Jones, Graham. (Ed.). Exploring probability in school: challenges for teaching and learning. Nova York: Springer, 2005.

[11] RENATA MORAES DE SANTANA, Michaelle. O acaso, o provável, o determinístico: concepções e conhecimentos probabilísticos de professores do ensino fundamental. 2011.

[12] REBOUÇAS, A. D. D. S.; Marques, D. L.; Costa, L. F. S.; Silva, M. A. A. (2010) "Aprendendo a Ensinar Programação Combinando Jogos e Python". In: XXI Simpósio Brasileiro de Informática na Educação - SBIE.

[13] SÁ, E. J. V; Teixeira, J. S. F; Fernandes, C. T. (2007) "Design de atividades de aprendizagem que usam Jogos como princípio para Cooperação”. In: XVIII Simpósio Brasileiro de Informática na Educação - SBIE. 
[14] SANTOS, Jaqueline. O movimento do pensamento probabilístico mediado pelo processo de comunicação com alunos do $7^{\circ}$ ano do Ensino Fundamental. 2010. 183f. Dissertação (Mestrado em Educação)-Programa de Pós-Graduação Stricto Sensu em Educação, Universidade São Francisco, Itatiba, 2010.

[15] SANTOS, Jaqueline Aparecida Foratto Lixandrão. A produção de significações sobre combinatória e probabilidade numa sala de aula do $6^{o}$ ano do Ensino Fundamental a partir de uma prática problematizadora. 2015. 191 p. Tese (Doutorado em Educação) - Programa de Pós-Graduação Stricto Sensu em Educação, Universidade São Francisco, Itatiba, 2015.

[16] WATSON, Jane M. Statistical literacy at school: growth na goals. New Jersey: Lawrence Erlbaum Associates Publishers, 2006.

Josevandro Barros Nascimento Universidade Federal da Paraíba Centro de Informática (CI) $<$ josevandrob@ppgmmc.ci.ufpb.br>

Jaqueline Aparecida Foratto Lixandrão Santos Universidade Federal de Pernambuco Centro Acadêmico do Agreste (CAA) <jaquelisantos@ig.com.br>

Sérgio de Carvalho Bezerra Universidade Federal da Paraíba Centro de Informática (CI) <sergio@ci.ufpb.br>

Recebido: 19/04/2021 Publicado: 06/07/2021 